\title{
State and federal fuel taxes: The road ahead for U.S. infrastructure funding
}

\author{
Jerome Dumortier, Fengxiu Zhang, and John Marron
}

April 2016

\section{SPEA AgEcon Papers}

2016-1

\section{Indianapolis Campus}

Indiana University - Purdue University Indianapolis

801 W. Michigan Street

Indianapolis, IN 46202-5752

www.spea.iupui.edu

\section{Bloom ington Campus}

Indiana University 1315E. Tenth Street Bloomington, IN47405-1701

www.indiana.edu/ -spea/

This is the author's manuscript of the article published in final edited form as:

Dumortier, J., Zhang, F., \& Marron, J. (2017). State and federal fuel taxes: The road ahead for U.S. infrastructure funding. Transport Policy, 53, 39-49. https://doi.org/10.1016/j.tranpol.2016.08.013 


\title{
State and federal fuel taxes: The road ahead for U.S. infrastructure funding
}

\author{
Jerome Dumortier $^{1}$, Fengxiu Zhang ${ }^{2}$, and John Marron $^{3}$ \\ ${ }^{1}$ School of Public and Environmental Affairs, Indiana University Purdue University Indianapolis \\ ${ }^{2}$ Center for Science, Technology \& Environmental Policy Studies, Arizona State University \\ ${ }^{3}$ Indiana University Public Policy Institute
}

April 2, 2016

\begin{abstract}
Taxes on gasoline and diesel are the primary sources of transportation funding at the state and federal level. Due to inflation and improved fuel efficiency, these taxes are increasingly inadequate to maintain the transportation system. In most states and at the federal level, the real fuel tax rates decrease because they are fixed at a cents-per-gallon amount rather than indexed to inflation. In this paper, we provide a forecast on state and federal tax revenue based on different fuel taxation policies such as indexing to inflation, imposing a sales tax on gasoline and diesel, or using a mileage fee on vehicles. We compare how those taxation policies perform compared to the policies states use currently under different macroeconomic conditions relating to the price of oil, economic growth, and vehicle miles traveled. The baselines projections indicate that between 2015 and 2040, fuel tax revenue will decrease 52.2\%-54.9\% in states that do not index taxes to inflation and $22.6 \%-22.9 \%$ that do currently index to inflation. Switching to a mileage fee increases revenue between $15.6 \%-26.9 \%$ in 2040 compared to 2015 . Indexing fuel taxes to inflation in addition to imposing a states' sales tax increases revenue significantly but suffers from a continuous decline in the long-run due to increased fuel efficiency. Our results indicate that although a mileage fee is politically and technologically difficult to achieve, it avoids a declining tax revenue in the long-run.
\end{abstract}

\section{Introduction}

Each state as well as the federal government taxes gasoline, diesel, and other fuels to finance the construction and maintenance of road infrastructure. Fuel taxes reflect an adoption of the benefit principle in the sense that consumers of the service pay for its provision based on their willingness to pay (Duncan and Graham, 2013). The fuel tax has the advantage that the implementation is relatively easy and that it is approximately proportional to the distance traveled (Forkenbrock, 
2005). Nevertheless, it is widely agreed that the motor fuel tax in the United States does not cover all direct and indirect costs (Goldman and Wachs, 2003; Parry and Small, 2005; TRB, 2006; Delucchi, 2007). Direct costs include the wear and tear to pavement done by motor vehicle travel and indirect costs include externalities such as congestion, accidents, and air pollution (CBO, 2011a). Besides not covering all cost of road travel, the revenue derived from fuel taxes in real terms has been stagnant and in some cases declining over the last decade, due mainly to an increase in fuel economy and fuel tax rates that are not adjusted to inflation. The economics and public finance literature covers well the equity and efficiency implications of various approaches of taxing and financing road travel, but it has not yet quantified the evolution of road funding availability in the future. The purpose of this article is to fill this gap and assess the future federal and state revenue associated with various taxing and revenue-generating schemes.

Fuel tax revenue is determined by the aggregate amount of gasoline and diesel purchased which in turn depends on multiple factors, including but not limited to fuel prices, tax rates, the number of vehicles, fuel economy, vehicle miles traveled per vehicle, and other factors. The current taxation structure and the fuel economy are the two main reasons for the stagnation of fuel tax rates in real terms (Greene, 2011; Gomez and Vassallo, 2013). First, the federal government as well as 35 states use a fixed cents-per-gallon tax. In 21 of those states, the last adjustment occurred before 2000 (FHWA, 2014). The non-adjustment of the cents-per-gallon tax leads to a decrease of the real fuel tax rate over time due to inflation. For example, the federal gasoline tax was set to \$0.184 in 1997. As a result of the increase in the Consumer Price Index (CPI) since 1997, the purchasing power of the tax rate declined by $31 \%$ by 2012. In 15 states, revenue is supplemented by a sales tax imposed on motor fuel sales. For example, Indiana continues the collection of a fixed cents-per-gallon fuel taxes and supplements the tax by a sales taxes based on previous months' fuel prices. Some states have chosen to use revenue from other taxes, mostly sales tax revenue, to cover shortfalls in transportation funding. This approach diminishes the resources available to support other stateprovided services and obligations. Other states have engaged in public-private partnerships and increased the use of tolling to generate more revenue. However, tolling systems are unlikely to be feasible as a funding approach; nor are toll fees likely to be equitable as this approach asks one segment of all transportation users (those using the toll roads) to finance a broader segment of the transportation system than from which they receive benefit.

Second, the increase in fuel efficiency is outpacing the increase in vehicle miles traveled (VMT). In 2012, the average fuel efficiency of the U.S. light-duty vehicle fleet was 23.3 and 17.1 miles per gallon (MPG) for short wheelbase and long wheelbase vehicles, respectively (U.S. DOT Bureau of Transportation Statistics, 2015). Newly sold passenger vehicles and light trucks have average fuel efficiencies of 36 and 25.3 MPG, respectively. Those values are expected to increase to 41.7 MPG by 2020 and to over 50 MPG by 2025 (EPA \& NHTSA, 2012). In addition to increases in fuel efficiency and inflation-driven decreasing tax revenues, the stagnation of VMT has exacerbated the decline in fuel tax receipts. After a steady upward trajectory throughout most of the past decades, total VMT in the United States has remained relatively flat since 2007 (USPIRG, 2013; FHWA, 2014). This may reflect a temporary change in driving habits during the recent economic recession and rebound along with economic recovery in the future.

Projections by the U.S. Energy Information Administration (EIA) under various macroeco- 

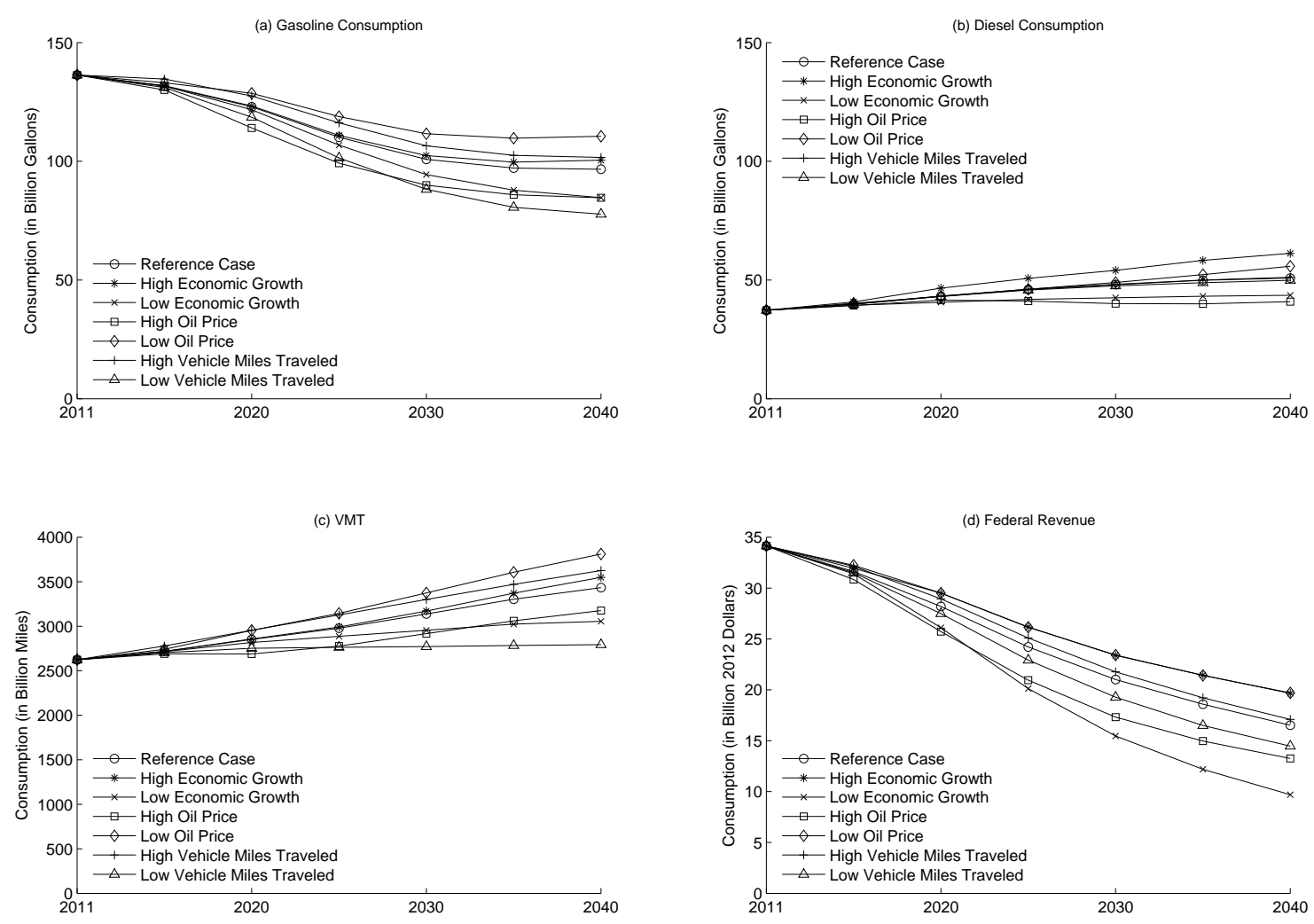

Figure 1: Consumption of gasoline and diesel (light duty vehicles and freight trucks), vehicle miles travelled (VMT), and fuel tax revenue from the federal gasoline and diesel taxes (in real terms) between 2015 and 2040 under various scenarios. The scenarios are based on the 2014 Annual Energy Outlook by the EIA (EIA, 2014).

nomic and driving scenarios indicate that, at least at the federal level, fuel tax revenue will continue to decline (EIA, 2014). Gasoline consumption will continue to decline in the future due to increasing fuel efficiency (Panel (a), Figure 2). Diesel consumption will increase due to an increasing number of freight trucks and stagnating fuel economy for heavy trucks (Panel (b), Figure 2). Despite the increase in diesel consumption and vehicle miles traveled (Panels (c), Figure 2), federal revenue from gasoline and diesel taxes will decline from $\$ 33.1$ billion in 2012 to $\$ 16.5$ billion in 2040 in the baseline case (Panels (d), Figure 2). This decline in federal revenue is based on the assumption of fuel tax rates not being adjusted to inflation. The revenue shortfall, in the absence of any policy adjustment, is expected to reach roughly $\$ 68$ and $\$ 133$ billion per year at the federal and state level, respectively (NSTIFC, 2009). In the very long-run, if the current vehicle fleet is replaced with an increasing number of highly fuel efficient or alternative fuel vehicles, e.g., plug-in hybrid or battery electric vehicles, the revenue from motor fuel taxes will decline further (Forkenbrock, 2005; McMullen et al., 2010). However, previous research has shown that this is not a significant issue in the time horizon considered in this analysis (Dumortier et al., 2015).

Through our analysis, we seek to project the state and federal revenue that is made available 
from vehicle travel under various tax policy, macroeconomic, and driving habit scenarios. The results can inform policy makers about the revenue that is potentially available for road and infrastructure funding. For this purpose, we develop a stylized simulation model based on projections from the 2014 EIA Annual Energy Outlook that covers the period from 2015 to 2040. The EIA cases vary by the macroeconomic framework, including projected economic growth and oil prices, as well as driving behavior in terms of vehicle miles traveled. Our model will impose different taxing schemes, such as a VMT fee, fuel tax indexation to inflation, on the EIA cases and compare those scenarios to the baseline. Using the EIA scenarios has the advantage that significant modeling has already been incorporated into the National Energy Modeling System (NEMS), thereby increasing the stability of the projections. We will look at three different tax policies for states and the federal government: (1) Indexing gasoline and diesel taxes to inflation, (2) applying state sales taxes to fuel prices in addition to the excise tax, and (3) implementing a VMT fee. We compare those tax policies with the current taxing schemes and assess under which circumstances a particular tax outperforms in terms of revenue generation. We find that the fuel tax revenue will decline by over 50\% between 2015 and 2040 in states that do not adjust fuel taxes to inflation. The decrease will be smaller, i.e., around $22 \%$, in states that currently adopt inflation-adjusted fuel taxes. This indicates that the fuel tax revenue shortfall is not solved by indexing taxes to inflation. Charging a VMT fee increases the tax revenue by $15.6 \%-26.9 \%$ by 2040 compared to the baseline. Imposing a sales tax in addition to the excise tax increases the revenue significantly at the beginning of the projection period but is reduces steadily over time due to improvements in the fuel efficiency. This paper contributes to the literature by informing policy makers, researchers, and other stakeholders about the future evolution of fuel tax revenue and the potential revenue impact under various taxing schemes and macroeconomic conditions.

\section{Literature Review}

There is an increasing gap between tax revenue derived from and cost of the U.S. transportation infrastructure (McMullen et al., 2010). Between 1980 and 2006, the vehicle miles traveled by automobiles and trucks increased by $97 \%$ and $104 \%$, respectively, while the number of new highway lanes increased by merely $4.4 \%$ (NSTIFC, 2009). Put differently, use of roadways has nearly doubled over the quarter of a century, while capacity on those roadways remained relatively constant. Between 1995 and 2014, the aggregate state motor fuel tax receipts have been almost constant, i.e., averaging $\$ 40.4$ billion in 2012 Dollars (FHWA, 2014). At the federal level, the fuel tax revenue is collected and disbursed via the Highway Trust Fund. Similar to the states, the revenue from gasoline and diesel taxes has been stagnating over the period 2000-2012 averaging \$36.3 billion. The balance of the Highway Trust Fund has been declining over time and Congress had to transfer a total of $\$ 65$ billion since 2008 to the Highway Trust Fund in order to keep it solvent (CBO, 2013, 2015).

An investigation of the existing literature finds a lingering and widespread concern regarding the decline in transportation funding over the past decade (Delucchi, 2007; Gale and Brown, 2013; Goldman and Wachs, 2003; Puentes and Prince, 2003; TRB, 2006; Wachs, 2003, 2006). Current state and federal revenues derived from fuel taxes are inadequate to support infrastructure funding 
needs for maintaining and improving the transportation network (TRB, 2011; CBO, 2011b, 2013). The inadequacy of fuel taxes most often results in disinvestment in the transportation network across many states, and the condition of the network deteriorates over time. Given the current and future shortfalls of the revenue derived from the fuel tax, new revenue-generating schemes have to be implemented sooner or later if an adequate infrastructure is to be maintained. In addition, due to the existing tax structure, road users do not necessarily recognize the direct link between their tax payment and the transportation system, reducing the recognition of the benefit they receive for the cost of the tax. Public finance researchers argue that the current motor fuel taxes lead to an inefficient use of roads for at least three reasons (Forkenbrock, 2005; NSTIFC, 2009): (1) most users are unaware of how much they pay in taxes, (2) fuel taxes do not account for the full cost of road use, and (3) fuel taxes are not linked to road system (e.g., interstate versus rural) or time-of-use (e.g., day versus night).

The basis for taxation of various revenue-generating systems can be broadly categorized into vehicle ownership (e.g., registration fees, licensing fees, etc.), highway user fees (VMT fees, tolling, congestion pricing, etc.), energy consumption (e.g., motor fuel taxes, sales taxes on fuels, etc.), and beneficiary/local option fees (e.g., transportation impact fee) (TRB, 2011). The numerous options proposed to bridge the financial gap include raising fuel taxes, providing toll roads and toll lanes, or instituting a user fee in the form of VMT charges (Goldman and Wachs, 2003; TRB, 2006; Schank and Rudnick-Thorpe, 2011). With respect to continuing the current system, there is a well-established literature on the efficiency and efficacy of fuel taxes in the United States. Parry and Small (2005) finds that the optimal gasoline tax is twice the current rate to include externalities such as pollution, congestion, and accidents. Similar values, i.e., $\$ 0.20-\$ 0.70$ per gallon, were found by Delucchi (2007) to balance driver payments and government spending on motor vehicles. Recently, there has been an interest in implementing VMT-based taxes to counteract the effect of increasing fuel efficiency (Dunn, 1993; TRB, 2006; Duncan and Graham, 2013). Under the current fuel tax system, fuel efficient vehicles pay less than other vehicles despite their similar contributions, relative to similarly sized vehicles, to road wear and tear. The politics of adopting a taxing structure that requires the government to monitor driving habits is politically or technologically difficult to achieve in the near term (Duncan and Graham, 2013). There is also widespread public opposition to the enactment of VMT-based taxes, with reasons including that the taxation is unfair to rural drivers, to people who drive more as part of their job, to people who drive fuel-efficient vehicles, and to people who are concerned about privacy issues (Duncan and Graham, 2013). The VMT fee does not encourage energy efficient vehicle design which could be cited as a potential disadvantage given the increasing concern about pollution and environmental damages (Austin and Dinan, 2005; Greene, 2011). Nevertheless, Parry and Small (2005) argues that most externalities are mileage driven and thus, the VMT fee would reduce externalities more than a fuel tax.

\section{Methods}

In this paper, we build a stylized simulation model around the 2014 Annual Energy Outlook (2014 AEO) published by the EIA. The advantage of using the 2014 AEO projections is that it already

takes into account the vehicle composition and fuel economy evolution based on macroeconomic 
parameters, technological progress, and policies. Thus, we assume that vehicle fuel economy and vehicle composition are exogenous to the model and variations based on fuel prices and policies are sufficiently captured by the model used for the 2014 AEO. The complete simulation model that was developed for this paper and its calibration are available in the Supplemental Information (SI).

In our model, we look at two distinct ways of taxing driving in the United States. A tax is either implemented on the amount of gasoline and diesel purchased or on the number of miles driven, i.e., a mileage fee. The tax on the amount of fuel purchased can be a per-unit tax that is either fixed, indexed to inflation, or supplemented by a sales tax. In all cases, tax revenue is a function of vehicle miles traveled, the vehicle fuel economy, and the number of vehicles. We assume that the vehicle miles traveled are a function of the cost-per-mile. In the most general form, cost per mile in state $i$ using fuel $j$ for vehicle type $k$ in time period $t$ is expressed as

$$
\begin{aligned}
c_{i j k t} & =\underbrace{\left(1+\lambda_{i j}^{p}\right) \frac{p_{i j t}}{m_{j k t}}}_{\text {fuel price }}+\underbrace{\left(1+\lambda_{i j}^{s}\right)\left(1+\pi_{t}\right) \frac{t_{i j}^{s}}{m_{j k t}}}_{\text {state fuel tax }}+\underbrace{\left(1+\lambda_{i j}^{h}\right)\left(1+\pi_{t}\right) \frac{t_{i j}^{h}}{m_{j k t}}}_{\text {state other taxes }} \\
& +\underbrace{\left(1+\lambda_{i j}^{f}\right)\left(1+\pi_{t}\right) \frac{t_{j}^{f}}{m_{j k t}}}_{\text {federal fuel tax }}+\underbrace{v_{i j t}^{s}+v_{i j t}^{f}}_{\text {VMT fee }}
\end{aligned}
$$

where $c_{i j k t}$ represents the cost per mile, $\lambda_{i j}^{p}$ represents the sales tax applied to the wholesale fuel price $p_{i j t}, \lambda_{i j}^{s}$ represents the sales tax on the state fuel tax, $\pi_{t}$ is the inflation, $t_{i j}^{s}$ represents the state's fuel tax, $\lambda_{i j}^{h}$ represents the sales tax on "other taxes," $t_{i j}^{h}$ represents "other taxes," and $m_{j k t}$ represents the fuel economy. The federal fuel tax rate and the state's sale tax on the federal tax are denoted $t_{j}^{f}$ and $\lambda_{i j}^{f}$, respectively. The VMT fees at the state and federal level are denoted $v_{i j t}^{s}$ and $v_{i j t}^{f}$, respectively. The equation (1) is flexible enough to accommodate the current as well as future highway funding policies analyzed in this paper.

We assume that the VMT for vehicle type $k$ in time period $t$ is a constant elasticity function of the price of fuel type $j$, i.e., gasoline, diesel, or E85 depending on the vehicle:

$$
V M T_{i j k t}=\alpha_{i j k t}\left(c_{i j k t} \cdot m_{j k t}\right)^{\eta_{j k}}
$$

where $\alpha_{i j k t}$ represents a state-specific constant and $\eta_{j k}$ is the elasticity with respect to the price of fuel. This formulation allows us to use literature elasticity estimates with respect to fuel prices.

We cover 19 different vehicle types in our simulation model. For gasoline and diesel vehicles, we have cars, light trucks, and light tractors, medium tractors, and heavy tractors. Gasoline vehicles also includes hybrids, plug-in hybrid vehicles (i.e., PHEV10 and PHEV40 ${ }^{1}$ ) and diesel vehicles include diesel hybrids. Flex fuel E85 vehicle types are limited to cars and light trucks. We also include battery electric vehicles that currently do not contribute to road maintenance but will be charged under the VMT fee scenarios.

\footnotetext{
${ }^{1}$ The numbers 10 and 40 for the PHEV10 and PHEV40 refer to the all-electric range in miles before switching to gasoline.
} 
The gasoline consumption for cars $\left(\mathrm{gas}_{c}\right)$, trucks ( $\left.\mathrm{gas}_{t}\right)$, conventional gasoline hybrids $($ hyg), and plug-in hybrid vehicles (PHV10 and PHV40) is written as

$$
C_{\text {gas }}=\delta_{j}+\sum_{j \in\left\{\text { gas }_{c}, g a a_{t}, h y g\right\}} S_{j} \cdot \frac{V M T_{j}}{M P G_{j}}+\sum_{j \in\{P H V 10, P H V 40\}} S_{j} \cdot \frac{V M T_{j} \cdot u f_{j}}{M P G_{j}}
$$

where $u f_{j}$ refers to the utility factor dividing the energy consumption of plug-in hybrid vehicles into a charge sustaining and charge depleting mode. Note that we dropped the state and year specific subscripts for ease of notation. The constant term $\delta_{j}$ is included to match the fuel consumption in the initial year to reported values. The charge sustaining mode refers to the condition where plug-in hybrids use gasoline or diesel to operate. In the charge depleting mode, i.e., depleting its battery, the plug-in hybrid vehicle uses the electric motor only. The equations for the consumption of diesel and E85 are written as

$$
\begin{aligned}
C_{t d i} & =\delta_{j}+\sum_{j \in\left\{t d i_{c}, t d i_{t}, h y d\right\}} S_{j} \cdot \frac{V M T_{j}}{M P G_{j}} \\
C_{E 85} & =\delta_{j}+\sum_{j \in\left\{E 85_{c}, E 85_{t}\right\}} S_{j} \cdot \frac{V M T_{j}}{M P G_{j}}
\end{aligned}
$$

Similarly, we assume a constant elasticity supply function for gasoline, diesel, and E85 that is written as

$$
M_{i}=\alpha p_{i}^{\beta_{i}} \quad \text { for } \quad i \in\{g a s, t d i, E 85\}
$$

CBO (2008) finds that a $20 \%$ increase in gasoline prices results in a 2.6 percentage points increase in the number of cars relative to light trucks. This inelastic response paired with the small changes in the tax burden imposed by our policy scenarios made us decide not to include vehicle substitution patterns for our policy scenarios. Note that vehicle substitutions is included in the EIA cases. The main driver for vehicle substitutions are the fuel prices and those variations are captured by the EIA.

The solution to the simulation model consists of a temporal series of wholesale prices, i.e., net of any tax, for gasoline, diesel, and E85 at the national level. We use a price transmission function based on historic data to translate the national wholesale prices for the three fuel types into state wholesale prices (EIA, 2016). This approach significantly reduces the computational time because the model solves for three price series instead of 153 (50 states plus Washington, D.C.). The resulting prices series clears the national market for all three fuels. Note that the implementation of the simulation model as well as the input data presented in the subsequent sections are available as supplementary material for this article.

\section{State Fuel Tax Rates}

A key component of our model is the parametrization of equation (1) because it captures the different policy scenarios analyzed in this paper. Table 1 summarizes the state parameters used for the baseline. The tax rates are compiled from three main sources: EIA (EIA, 2015), Federation of Tax 
Administrators (FTA, 2015), and the American Petroleum Institute (API, 2016). For the E85 tax rates, we rely solely on the numbers published by (FTA, 2015) since the other sources do not list the rates. The tax rates reported by EIA are current as of September 2015 and the rates published by the other sources are current as of January 2016.

There is a wide variety of taxing schemes with intra-state variations, exemptions, etc. Table 1 represents the state-wide tax rates and does not take into account county and other local taxes. Small differences exist between the sources due to publication date since some states index their taxes to inflation frequently and/or impose a sales tax in addition to a fixed-per-gallon rate. For example, Maryland has a motor fuel tax on gasoline of $\$ 0.235$ per gallon but adds an inflation component of $\$ 0.011$ per gallon. Since we continue to impose the inflation component, the resulting excise tax is $\$ 0.246$ per gallon. In case of differences, we check the rates on the respective states webpage. Some states have started to adopt some version of variable rates (in many cases, additional to the fixed cost base fuel tax). These taxes are often linked to the price of fuel or some measure of inflation. The price of fuel is quite volatile from year to year; as a result, variable rate structures that are tied to the price of fuel can make it difficult for transportation agencies to accurately project revenue, which therefore creates challenges in budgeting. States that impose a sales taxes on some or all motor fuels are Alaska (1.1\%, all cities and boroughs), California (2.25\% for gasoline and E85, 9.42\% on diesel), Connecticut (8.1\% only gasoline only, capped at a price of $\$ 3$ per gallon excluding excise tax), Florida (on excise only), Georgia, Hawaii, Illinois (E85 exempt), Indiana (on excise only), Michigan, New York, Vermont (4\%), Virginia (2.1\% in in some districts and on excise only), and West Virginia (5\% on excise only). Arizona has a tax of $\$ 0.27$ for heavy duty diesel trucks. Note that Alaska, Delaware, Montana, New Hampshire, and Oregon do not have a sales tax. For those states, the scenarios imposing a sales tax will be replaced with the baseline taxing schemes and thus, the results from the sales taxes scenarios will not be comparable to the baseline for those states. The tax rates in Kentucky and Nebraska vary with the gasoline price. Voters in Massachusetts repealed the indexing of fuel taxes to inflation in November 2014 which leaves Florida, Maryland, and New Hampshire as being the only states who fully adjust their tax to inflation (API, 2016).

We impose state-level VMT-fees for five vehicle categories: (1) cars, (2) light trucks, (3) light-, (4) medium-, and (5) heavy-duty freight vehicles. This categorization groups vehicles of similar weights in one category. Since we assume that motor fuel taxes as well as VMT-fees are implemented to pay for road wear and tear, vehicles that have a similar weight and thus, cause similar damage, should pay the same amount. The VMT fee corresponds to the excise tax levied in each state translated on a cost per mile basis. At the federal level, the VMT fees are $\$ 0.008, \$ 0.011$, $\$ 0.018, \$ 0.028, \$ 0.033$ for cars, light trucks, light-, medium-, and heavy-duty freight vehicles, respectively.

\section{Data}

Our main source of data for this analysis is the 2014 AEO (EIA, 2014) but we also rely on estimates from the literature to supplement missing or inconsistent data. The 2014 AEO comprises a reference case which assumes no change in current policies and an average annual growth of 


\begin{tabular}{|c|c|c|c|c|c|c|c|c|c|c|c|c|}
\hline \multirow[t]{2}{*}{ State } & \multicolumn{2}{|c|}{ Gasoline } & \multicolumn{2}{|c|}{ Diesel } & \multicolumn{2}{|c|}{ E85 } & \multirow{2}{*}{$\begin{array}{c}\text { Sales } \\
\text { Tax }(\%)\end{array}$} & \multicolumn{5}{|c|}{ VMT-fee (cents per mile) } \\
\hline & Excise & Other & Excise & Other & Excise & Other & & Car & LT & FL & FM & FH \\
\hline Alabama & 16.0 & 3.0 & 19.0 & 1.8 & 16.0 & 2.0 & $4.00 \%$ & 0.69 & 0.94 & 1.48 & 2.40 & 3.38 \\
\hline Alaska & 8.0 & 1.0 & 8.0 & 1.0 & 8.0 & & & 0.34 & 0.47 & 0.63 & 1.01 & 1.42 \\
\hline Arizona & 18.0 & 1.0 & 18.0 & 1.0 & 18.0 & 1.0 & $5.60 \%$ & 0.77 & 1.05 & 1.41 & 2.27 & 3.20 \\
\hline Arkansas & 21.5 & 0.3 & 22.5 & 0.3 & 21.5 & 0.3 & $6.50 \%$ & 0.92 & 1.26 & 1.76 & 2.84 & 4.00 \\
\hline California & 30.0 & 7.2 & 13.0 & 24.7 & 36.0 & 6.5 & $7.50 \%$ & 1.29 & 1.75 & 1.02 & 1.64 & 2.31 \\
\hline Colorado & 22.0 & 1.3 & 20.5 & 1.3 & 20.0 & & $2.90 \%$ & 0.94 & 1.29 & 1.60 & 2.58 & 3.65 \\
\hline Connecticut & 25.0 & & 50.3 & & 25.0 & & $6.35 \%$ & 1.07 & 1.46 & 3.93 & 6.34 & 8.95 \\
\hline Delaware & 23.0 & & 22.0 & & 23.0 & & & 0.99 & 1.35 & 1.72 & 2.77 & 3.91 \\
\hline D.C. & 23.5 & 0.0 & 23.5 & 0.0 & 23.5 & 0.0 & $5.75 \%$ & 1.01 & 1.37 & 1.84 & 2.96 & 4.18 \\
\hline Florida & 4.0 & 26.6 & 4.0 & 29.7 & 4.0 & 24.5 & $6.00 \%$ & 0.17 & 0.23 & 0.31 & 0.50 & 0.71 \\
\hline Georgia & 26.0 & 0.5 & 29.0 & 0.5 & 7.5 & 11.8 & $4.00 \%$ & 1.12 & 1.52 & 2.27 & 3.66 & 5.16 \\
\hline Hawaii & 17.0 & 2.5 & 17.0 & 2.5 & 17.0 & & $4.00 \%$ & 0.73 & 0.99 & 1.33 & 2.14 & 3.03 \\
\hline Idaho & 32.0 & 1.0 & 32.0 & 1.0 & 25.0 & 1.0 & $6.00 \%$ & 1.37 & 1.87 & 2.50 & 4.03 & 5.69 \\
\hline Illinois & 19.0 & 15.1 & 21.5 & 15.1 & 19.0 & 1.1 & $6.25 \%$ & 0.82 & 1.11 & 1.68 & 2.71 & 3.83 \\
\hline Indiana & 18.0 & 16.8 & 16.0 & 1.0 & 18.0 & & $7.00 \%$ & 0.77 & 1.05 & 1.25 & 2.02 & 2.85 \\
\hline Iowa & 30.8 & 1.0 & 32.5 & 1.0 & 29.3 & 1.0 & $6.00 \%$ & 1.32 & 1.80 & 2.54 & 4.10 & 5.78 \\
\hline Kansas & 24.0 & 1.0 & 26.0 & 1.0 & 24.0 & 1.0 & $6.15 \%$ & 1.03 & 1.40 & 2.03 & 3.28 & 4.63 \\
\hline Kentucky & 24.6 & 1.4 & 21.6 & 1.4 & 26.2 & 1.4 & $6.00 \%$ & 1.06 & 1.44 & 1.69 & 2.72 & 3.84 \\
\hline Louisiana & 20.0 & 0.9 & 20.0 & 0.9 & 20.0 & 0.1 & $4.00 \%$ & 0.86 & 1.17 & 1.56 & 2.52 & 3.56 \\
\hline Maine & 30.0 & 1.4 & 31.2 & 0.7 & 30.0 & & $5.50 \%$ & 1.29 & 1.75 & 2.44 & 3.93 & 5.55 \\
\hline Maryland & 24.6 & 7.7 & 25.4 & 7.7 & 30.3 & & $6.00 \%$ & 1.06 & 1.44 & 1.98 & 3.20 & 4.51 \\
\hline Massachusetts & 24.0 & 2.6 & 24.0 & 2.6 & 24.0 & & $6.25 \%$ & 1.03 & 1.40 & 1.88 & 3.03 & 4.27 \\
\hline Michigan & 19.0 & 14.7 & 15.0 & 16.1 & 19.0 & & $6.00 \%$ & 0.82 & 1.11 & 1.17 & 1.89 & 2.67 \\
\hline Minnesota & 28.5 & 0.1 & 28.5 & 0.1 & 28.5 & 0.1 & $6.88 \%$ & 1.22 & 1.67 & 2.23 & 3.59 & 5.07 \\
\hline Mississippi & 18.0 & 0.4 & 18.0 & 0.4 & 18.0 & 0.4 & $7.00 \%$ & 0.77 & 1.05 & 1.41 & 2.27 & 3.20 \\
\hline Missouri & 17.0 & 0.3 & 17.0 & 0.3 & 17.0 & 0.3 & $4.23 \%$ & 0.73 & 0.99 & 1.33 & 2.14 & 3.03 \\
\hline Montana & 27.0 & 0.8 & 27.8 & 0.8 & 27.0 & & $0.00 \%$ & 1.16 & 1.58 & 2.17 & 3.50 & 4.94 \\
\hline Nebraska & 26.8 & 0.9 & 26.8 & 0.3 & 25.6 & 0.9 & $5.50 \%$ & 1.15 & 1.57 & 2.09 & 3.38 & 4.77 \\
\hline Nevada & 23.0 & 0.8 & 27.0 & 0.8 & 23.0 & 0.8 & $6.85 \%$ & 0.99 & 1.35 & 2.11 & 3.40 & 4.80 \\
\hline New Hampshire & 22.2 & 1.6 & 22.2 & 1.6 & 22.2 & 1.6 & $0.00 \%$ & 0.95 & 1.30 & 1.73 & 2.80 & 3.95 \\
\hline New Jersey & 10.5 & 4.1 & 13.5 & 4.1 & 10.5 & 4.0 & $7.00 \%$ & 0.45 & 0.61 & 1.05 & 1.70 & 2.40 \\
\hline New Mexico & 17.0 & 1.9 & 21.0 & 1.9 & 17.0 & 1.9 & $5.13 \%$ & 0.73 & 0.99 & 1.64 & 2.65 & 3.74 \\
\hline New York & 8.0 & 26.1 & 8.0 & 24.3 & 8.0 & 17.8 & $4.00 \%$ & 0.34 & 0.47 & 0.63 & 1.01 & 1.42 \\
\hline North Carolina & 36.0 & 0.3 & 36.0 & 0.3 & 37.5 & 0.3 & $4.75 \%$ & 1.55 & 2.11 & 2.81 & 4.54 & 6.41 \\
\hline North Dakota & 23.0 & & 23.0 & & 23.0 & & $5.00 \%$ & 0.99 & 1.35 & 1.80 & 2.90 & 4.09 \\
\hline Ohio & 28.0 & & 28.0 & & 28.0 & & $5.75 \%$ & 1.20 & 1.64 & 2.19 & 3.53 & 4.98 \\
\hline Oklahoma & 16.0 & 1.0 & 13.0 & 1.0 & 16.0 & 1.0 & $4.50 \%$ & 0.69 & 0.94 & 1.02 & 1.64 & 2.31 \\
\hline Oregon & 30.0 & & 30.0 & & 30.0 & & $0.00 \%$ & 1.29 & 1.75 & 2.34 & 3.78 & 5.34 \\
\hline Pennsylvania & 50.3 & 1.1 & 64.0 & 1.1 & 50.5 & & $6.00 \%$ & 2.16 & 2.94 & 5.00 & 8.07 & 11.39 \\
\hline Rhode Island & 33.0 & 1.1 & 33.0 & 1.1 & 32.0 & 1.0 & $7.00 \%$ & 1.42 & 1.93 & 2.58 & 4.16 & 5.87 \\
\hline South Carolina & 16.0 & 0.8 & 16.0 & 0.8 & 16.0 & 0.8 & $6.00 \%$ & 0.69 & 0.94 & 1.25 & 2.02 & 2.85 \\
\hline South Dakota & 28.0 & 2.0 & 28.0 & 2.0 & 22.0 & 2.0 & $4.00 \%$ & 1.20 & 1.64 & 2.19 & 3.53 & 4.98 \\
\hline Tennessee & 20.0 & 1.4 & 17.0 & 1.4 & 20.0 & 1.4 & $7.00 \%$ & 0.86 & 1.17 & 1.33 & 2.14 & 3.03 \\
\hline Texas & 20.0 & & 20.0 & & 20.0 & & $6.25 \%$ & 0.86 & 1.17 & 1.56 & 2.52 & 3.56 \\
\hline Utah & 24.5 & 0.7 & 24.5 & 0.7 & 24.5 & & $5.95 \%$ & 1.05 & 1.43 & 1.91 & 3.09 & 4.36 \\
\hline Vermont & 12.1 & 18.7 & 28.0 & 4.0 & 18.2 & 13.8 & $6.00 \%$ & 0.52 & 0.71 & 2.19 & 3.53 & 4.98 \\
\hline Virginia & 16.2 & 0.6 & 20.2 & 0.6 & 16.2 & & $5.30 \%$ & 0.70 & 0.95 & 1.58 & 2.55 & 3.59 \\
\hline Washington & 44.5 & 0.1 & 44.5 & 0.1 & 37.5 & & $6.50 \%$ & 1.91 & 2.60 & 3.48 & 5.61 & 7.92 \\
\hline West Virginia & 20.5 & 14.1 & 20.5 & 14.1 & 20.5 & 14.1 & $6.00 \%$ & 0.88 & 1.20 & 1.60 & 2.58 & 3.65 \\
\hline Wisconsin & 30.9 & 2.0 & 30.9 & 2.0 & 30.9 & 2.0 & $5.00 \%$ & 1.33 & 1.81 & 2.41 & 3.90 & 5.50 \\
\hline Wyoming & 23.0 & 1.0 & 23.0 & 1.0 & 23.0 & 1.0 & $4.00 \%$ & 0.99 & 1.35 & 1.80 & 2.90 & 4.09 \\
\hline
\end{tabular}

Table 1: Summary of state tax rates in cents per mile for gasoline, diesel, and E85. Not in all states is the sales tax imposed on motor fuel equivalent to the general sales tax. We have removed the sales tax component in the category "Other" to avoid double counting. VMT-fee: Light-trucks (LT), freight light (FL), freight medium (FM), freight heavy (FH). 
gross domestic product by 2.4 percent until 2040. In addition, it assumes an oil price of $\$ 141$ (in 2012 dollars) at the end of the projection period. Besides the reference case, the EIA simulates an additional 29 scenarios representing varying macroeconomic environments, policies, and driving habits. With gasoline and diesel consumption being the main driver for fuel tax revenue, we chose six scenarios besides the reference case that are most influential on those variables: (1) Low Economic Growth, (2) High Economic Growth, (3) Low Oil Price, and (4) High Oil Price, (5) Low VMT, and (6) High VMT. The scenarios "Low VMT" and "Low Oil Price" capture the lowest and highest gasoline consumption across all scenarios. Since fuel consumption depends on economic conditions, the price of oil, as well as VMT, those scenarios are the most relevant to our research questions. First, economic growth influences the number of vehicles purchased and thus, the stock of vehicles as well as the VMT. Second, the oil price influences driving behavior and fuel consumption via the price of gasoline and diesel. And third, gasoline and diesel consumption depends on the amount of and variation in miles driven that might reflect general changes in driving behavior (USPIRG, 2013).

A total of 19 vehicle categories are modeled. The 2014 AEO reports the vehicle stock projections for all scenarios at the national level but not at the state-level and thus, we rely on 2013 data from the Federal Highway Administration (FHWA) to allocate the aggregate estimates to the states (FHWA, 2014). The FHWA reports state-level statistics from automobiles, buses, trucks (truck tractors, pickups, vans, sport utility vehicles), and motorcycles differentiated by public and private ownership. In order to match the state-level vehicle distribution, we assume that the categories autos, vans, and sport utility vehicles correspond to the cars category in the 2014 AEO.

There are significant variations in the vehicle miles traveled by state (USPIRG, 2013; FHWA, 2014). Variations are due to the physical size of a state, population density, urban vs. rural driving, economic activity, etc. Reliable estimates by state and vehicle category are difficult to obtain. The FHWA provides estimates by state, vehicle, and road type, e.g., urban interstate, rural arterial, etc., but the resulting VMT by vehicle and state does not match expectations except for light duty vehicles. We hypothesize that this mismatch, especially for trucks, is due to significant travel between states and thus, the vehicles registered in one state are not a good indicator for how much fuel is consumed in a particular state. For our model, we use only the FHWA estimates for the light duty cars. For light duty vehicles in 2013, the FHWA reports 11,244 and 11,717 VMT per year for long and short wheelbase, respectively. For 2014, the difference is almost 10 percent between the short and long wheelbase vehicles. Thus, we assume that the VMT for light trucks (largely corresponding to the long wheelbase category) is 10 percent higher than for cars.

The consumption of gasoline and diesel was transformed from British Thermal Units (BTU) to gallons using a lower heating value energy content of $116,090 \mathrm{BTU}_{\text {gal. }}{ }^{-1}$ and 128,488 BTU gal. $^{-1}$, respectively (U.S. DOE Alternative Fuels Data Center, 2015). The energy content of E85 is calculated as the weighted average of the energy content of ethanol, i.e., 76,330 BTU gal. ${ }^{-1}$, and gasoline. For the fuel economy of conventional gasoline vehicles in the first year, we assume 23.3 and 17.1 MPG for cars and trucks, respectively (U.S. DOT Bureau of Transportation Statistics, 2015). For conventional hybrids, we use a fuel economy of 43.7 and 40.6 MPG for highway and urban driving, respectively (Al-Alawi and Bradley, 2013). For plug-in hybrid vehicles, the utility factors for PHV10 and PHV40 mid-sized vehicles are taken from Al-Alawi and Bradley 
(2013). The utility factor for urban and highway are 0.32 and 0.12 for PHV10 and 0.79 and 0.41 for PHV40. Assuming highway driving of $45 \%$, we calculate a weighted utility factor of 0.1829 and 0.5575 for PHEV10 and PHEV40, respectively. The highway and urban driving MPG for PHEV10 in charge sustaining mode is 40.75 and 45.40, respectively. The values for the PHEV40 are 41.65 and 48.4 MPG. For the diesel consumption of the current fleet, we assume that the ratio of gasoline to diesel fuel economy is the same as for new cars sold which is reported by the AEO. We then calculate the implicit diesel fuel economy of vehicles currently on the road that matches the AEO projections. This results in a diesel fuel economy of 44.15 and 34.26 MPG for cars and light trucks, respectively. For E85, the reduction in fuel economy compared to a gasoline vehicle varies between $15 \%$ and $30 \%$ depending on the content of ethanol in the fuel mix (DOT, 2015). We use the maximum value of $30 \%$ reduction in our model since this corresponds to the difference in energy content between gasoline and E85.

To parameterize the elasticities in our model, we rely on estimates from the literature. A metaanalysis found that on average, the demand elasticity of gasoline demand is -0.26 in the short run (defined as one year or less) and -0.58 in the long run (Espey, 1996). However, since the late 1990s, studies have found a shift to inelasticity, meaning that consumers are less sensitive to price changes (Cooper, 2003; Hughes et al., 2008; Park and Zhao, 2010) and an elasticity of -0.034 in the short run is more appropriate. Other studies found a short-run elasticity of -0.061 and a long-run elasticity of -0.453 (Cooper, 2003). So given the elasticity of gasoline of -0.453 , a $1 \%$ increase in the cost of gasoline leads to a reduction in the quantity consumed by $0.453 \%$. Austin and Dinan (2005) report elasticities between -0.1 and -0.3 for the price of gasoline with respect to VMT, i.e., an increase in the price of gasoline by $1 \%$ results in a reduction in VMT by $0.1 \%-0.3 \%$. For our model, we pick the middle value of -0.2 . Bento et al. (2009) estimated the elasticity of VMT with respect to operating cost and and found an average value of -0.74 for all vehicles in their sample with small trucks being more price response than mid-sized cars. Few recent estimates of diesel fuel price elasticity exist. The long-run elasticity for diesel was found to be -0.4 in and -0.24 to -0.04 for the short-run (Parry, 2006). For diesel and E85 vehicles, we pick an elasticity value of -0.3 . For heavy trucks, Leard et al. (2015) report an elasticity of -0.169 which is the value assumed for our freight trucks.

Given our model and the parametrization, we run a baseline that leaves all the parameters at their status quo values. When compared with the values from the 2014 AEO reference case, the consumption of gasoline and diesel are within $1.5 \%$ and $5.6 \%$, respectively. The data provided in the 2014 AEO for E85 led to unrealistically high estimates for the fuel economy. Thus, we relied on the fuel economy being $30 \%$ of their conventional counterparts.

\section{Analysis and Results}

For each of the seven EIA cases, we run seven tax policy scenarios. The first scenario ("Baseline") represents the status quo in which states remain with their current policy and the federal government keeps the gasoline and diesel tax at \$0.184 and \$0.224, respectively. In the next scenarios, we (1) index the state fuel taxes to inflation, (2) impose a state sales tax in addition to the current excise taxes, and (3) impose a VMT fee at the state level. For those three scenarios, we also index the 


\begin{tabular}{|c|c|c|c|c|c|c|c|}
\hline & \multicolumn{4}{|c|}{ State Policy } & \multicolumn{3}{|c|}{ Federal Policy } \\
\hline & Excise & CPI & Sales & VMT & Excise & CPI & VMT \\
\hline Baseline & \multicolumn{7}{|c|}{ Current policy in all states } \\
\hline $\mathrm{CPI} / \mathrm{CPI}$ & - & - & & & - & - & \\
\hline Sales/CPI & - & & - & & - & - & \\
\hline VMT/CPI & & & & - & - & - & \\
\hline $\mathrm{CPI} / \mathrm{VMT}$ & - & - & & & & & - \\
\hline Sales/VMT & - & & - & & & & - \\
\hline VMT/VMT & & & & - & & & - \\
\hline
\end{tabular}

Table 2: Summary of baseline and policies run for each of the seven EIA scenarios. Note that the "current policy in all states" reflects tax rates from January 2016.

federal tax rates to inflation. We call those scenarios "CPI/CPI," "Sales/CPI," and "VMT/CPI." We run three additional scenarios under the assumption of a federal VMT-fee instead of an inflationadjusted fuel tax. Those scenarios are called "CPI/VMT," "Sales/VMT," and "VMT/VMT" (Table 2). The VMT fee is held constant in real terms over the projection period which is one on the suggestions made in NSTIFC (2009). Otherwise, the VMT fee would face the same issue as the motor fuel tax currently does, i.e., decrease in real terms. We also assume that the revenue generated from the excise tax and the sales tax is made available for road transportation funding over the entire projection period. The amount of revenue generated from "other taxes" is not included in our results graphs since it is usually used environmental purposes and leaking underground storage tanks. Note that the distribution method of funds generated from motor vehicles varies by state and thus, we report we only exclude the revenue generated from other taxes in the numbers reported below.

For all EIA cases and all states, the states' tax revenue under the current policies will decrease between 2015 and 2040. In the reference case, the median decrease is 54\% (Figure 2) with a maximum decrease of $73 \%$ in the low economic growth case and a minimum of $43 \%$ in the low oil price case. There are variations among the states depending on whether fuel taxes are adjusted to inflation or not. Florida, Maryland, and New Hampshire see a decrease between $12 \%$ to $23 \%$ despite the fact that those states adjust their motor fuel taxes to inflation. Decreasing revenue in the presence of inflation-adjusted fuel taxes are due to increasing fuel efficiency. States that currently supplement the motor fuel taxes with an additional sales tax do not see a decrease as severe as states without any sales or inflation-adjusted motor fuel tax. But there is still a decrease between $25 \%$ and $44 \% .^{2}$ Note that the decrease is significantly higher under the low economic growth scenario and lowest under the low oil price scenarios. Under the low oil price scenario, the variance between the decrease in state revenues is also lower than in the reference case. The reason for the reduced variance is due to the sales tax not contributing as much to the revenue than under the baseline.

\footnotetext{
${ }^{2}$ This does not include the $12 \%$ decrease in Florida since the state indexes tax to inflation in addition to having a sales tax.
} 


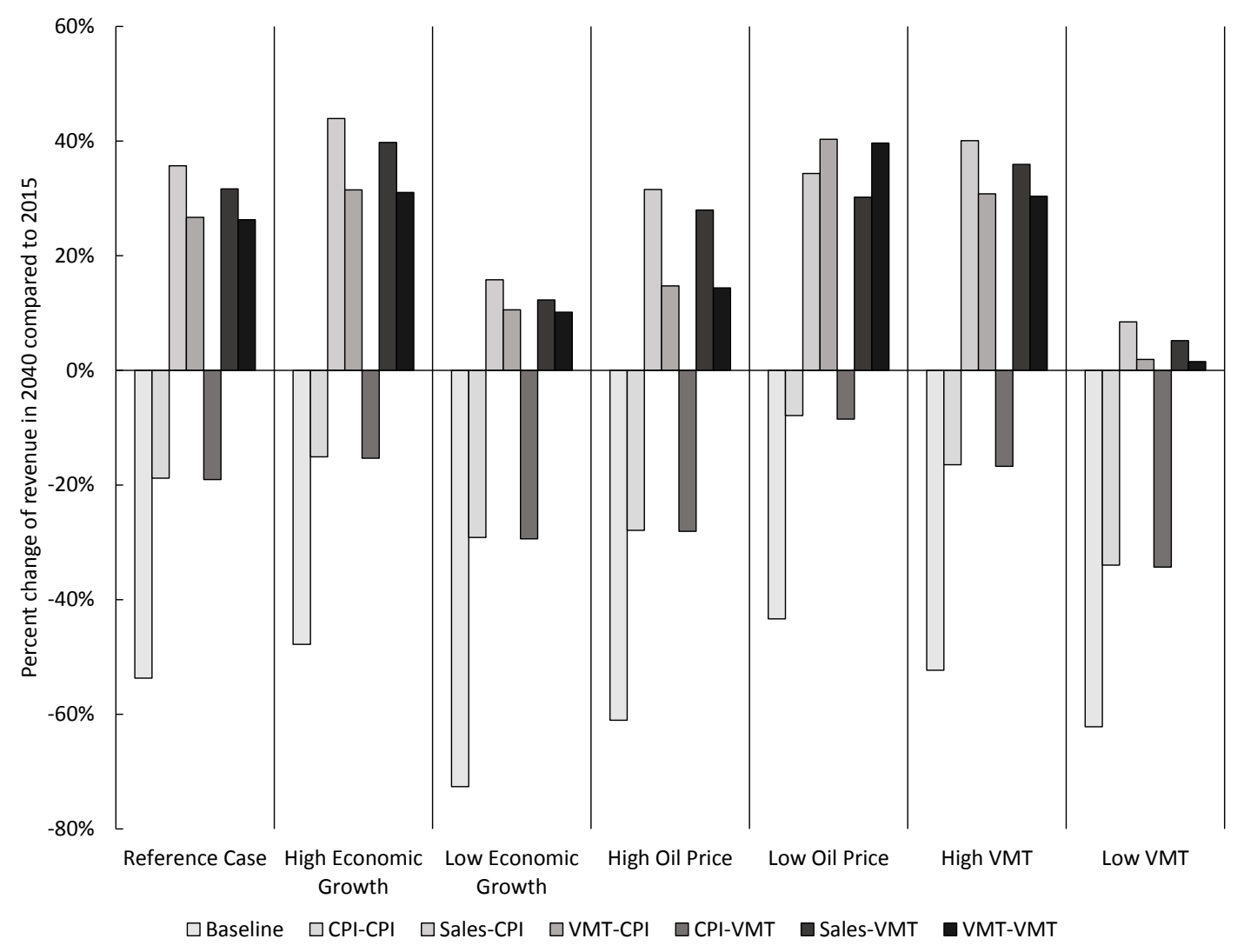

Figure 2: Median change in motor fuel tax and VMT fee revenue for 50 states and D.C. for EIA cases and tax policy scenarios.

In the second policy scenario where we adjust fuel taxes to inflation in all states and assume a removal of a sales taxes, we find it represents a considerable improvement for most states compared to the baseline scenarios. The median decrease in the reference case is $19 \%$ and as in the baseline scenarios, the decrease in revenue between 2015 and 2040 is minimal in the low oil price case (8\% decrease). The maximum decrease happens in the low VMT scenario. Note that the results are relatively stable under both federal policies. Whether the federal government uses an inflationadjusted fuel tax rate or a VMT-fee, the change in state fuel tax revenue is almost unaffected.

Linking the fuel tax to inflation does not disconnect the motor fuel tax revenue from the increase in fuel efficiency. A closer look at the scenarios in which an additional sales tax is imposed on the inflation-adjusted fuel tax versus the VMT fee illustrates this issue (Figure 3). The tax revenue from imposing the states' sales taxes on top of the inflation-adjusted excise taxes will lead to a significant increase in tax revenue in 2040 compared to 2015. In the reference scenario, the median tax revenue is $35 \%$ and $31 \%$ higher under a federal inflation-adjusted tax and VMT-fee, 

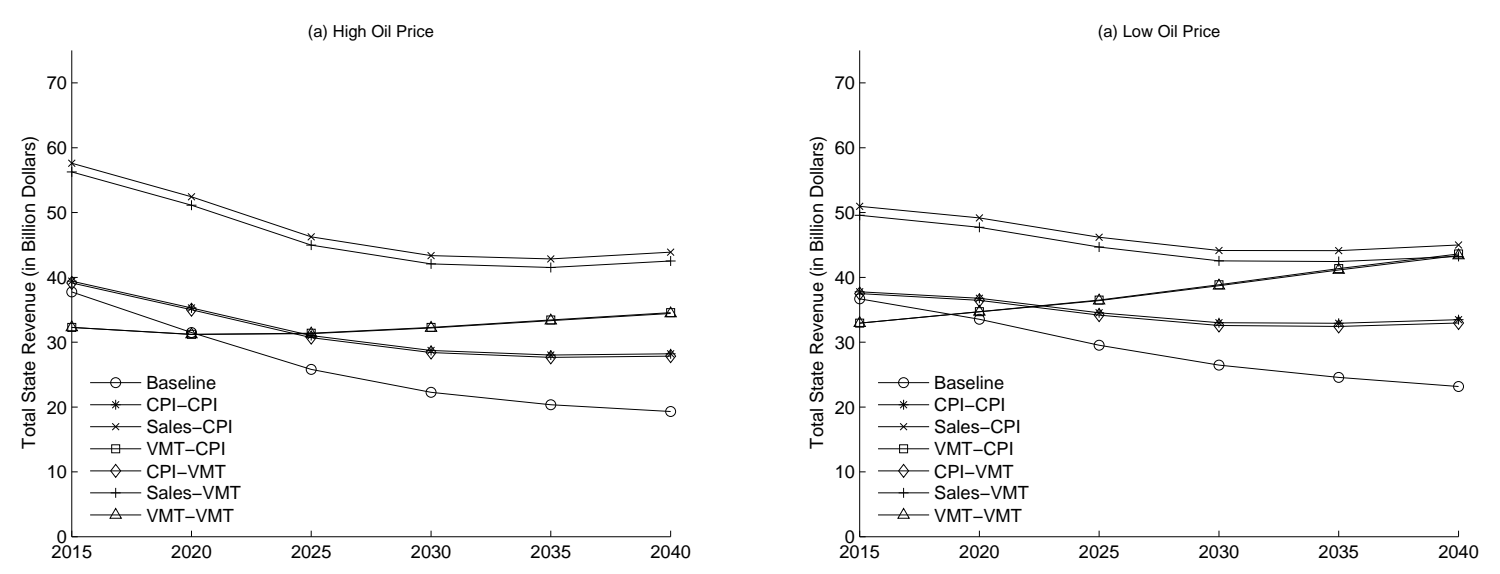

Figure 3: Evolution of total state revenue under high and low oil price scenario with differential results for a combined inflation-adjusted fuel tax combined with a sales tax versus a VMT-fee.

respectively. In 2040, the additional revenue from the sales tax exceeds the revenue derived from a VMT fee for all EIA cases except in the scenario of low oil prices. This result is straightforward since the sales tax on motor fuel is highest under high gasoline and diesel prices. In the case of low fuel prices resulting from a low oil price, revenue is modest. The second issue associated with the sales tax in addition to the CPI-indexed motor fuel tax is its dependence on fuel efficiency. Despite resulting in a high revenue at the beginning of the period, the revenue is decreasing over time since it is still dependent on the fuel efficiency of cars. Hence, coupling a CPI-adjusted tax with a sales tax has some short- to medium-run benefits if the oil price is high but in the long-run it faces the exact same issue as the current taxing scheme in the sense that it is declining with increasing fuel efficiency.

In the scenario where we impose a VMT fee in the amount of the current states' excise tax, the increase in revenue is linked to the number of vehicles on the road and the amount of miles driven. From a revenue perspective, this is the only scenario that is sustainable in the long-run since it is not linked to fuel economy. Note that our results also include battery electric vehicles that were not included in the previous scenarios since they do not use motor fuel. Dumortier et al. (2015) has shown that the number of battery electric vehicles is low in the short- to medium-run and thus, they do not contribute significantly to revenue stream and the state and federal level.

Besides the impact on tax revenue, policy makers are interested in the financial effects on individual drivers in terms of cost-per-mile. Table 3 indicates that for cars and light trucks, which constitute the majority of vehicles on the road, the sales-weighted cost per mile across all EIA cases and all policy scenario decreases. This is a direct consequence of the increasing fuel efficiency which outpaces growth in vehicle miles traveled. Differences between the minimum and maximum values respectively in table 3 are due to the different tax policies. In this context, it is important to understand that the cost per driver is decreasing under all tax scenarios and a change in tax rate only determines how much the cost per mile decreases and not whether it increases or decreases. Note that for medium- and heavy-duty trucks, the fuel efficiency is not improving significantly 


\begin{tabular}{|c|c|c|c|c|c|c|}
\hline & & \multirow[b]{2}{*}{ Cars } & \multirow[b]{2}{*}{ Light Trucks } & \multicolumn{3}{|c|}{ Freight Trucks } \\
\hline & & & & Light & Medium & Heavy \\
\hline \multirow[t]{2}{*}{ Baseline } & Min & -38.2 & -37.9 & -21.9 & -16.1 & 2.1 \\
\hline & Max & -23.0 & -22.4 & 2.8 & 10.0 & 36.5 \\
\hline \multirow[t]{2}{*}{$\mathrm{CPI} / \mathrm{CPI}$} & Min & -36.5 & -36.0 & -20.0 & -14.1 & 4.6 \\
\hline & Max & -21.7 & -21.0 & 4.0 & 11.5 & 38.2 \\
\hline \multirow[t]{2}{*}{ Sales/CPI } & Min & -36.5 & -36.0 & -20.0 & -14.1 & 4.6 \\
\hline & Max & -21.8 & -21.0 & 4.0 & 11.5 & 38.2 \\
\hline \multirow[t]{2}{*}{ VMT/CPI } & Min & -34.6 & -34.5 & -19.0 & -13.4 & 4.0 \\
\hline & Max & -20.0 & -19.6 & 6.2 & 13.6 & 39.3 \\
\hline \multirow[t]{2}{*}{ CPI/VMT } & Min & -35.3 & -35.1 & -19.3 & -13.7 & 3.8 \\
\hline & Max & -20.7 & -20.1 & 5.6 & 12.8 & 38.9 \\
\hline \multirow[t]{2}{*}{ Sales/VMT } & Min & -35.3 & -35.1 & -19.3 & -13.7 & 3.8 \\
\hline & Max & -20.7 & -20.1 & 5.6 & 12.8 & 38.9 \\
\hline \multirow[t]{2}{*}{ VMT/VMT } & Min & -33.4 & -33.6 & -18.1 & -12.9 & 3.2 \\
\hline & Max & -19.0 & -18.7 & 7.9 & 15.1 & 40.1 \\
\hline
\end{tabular}

Table 3: Highest and lowest percent change in sales-weighted cost per mile under EIA cases and policy scenarios.

over the projection period and thus, those vehicles are more exposed to the increase in fuel price, e.g., under the high oil price scenario, than the light trucks and cars. Figure 4 summarizes the absolute amount of sales-weighted cost-per-mile for the various vehicles in our analysis. Again, the minimum and maximum values are driven by differences in the EIA cases and the variation across the different tax policies is small. This is due to the fact that the taxes are only a relatively small proportion of the overall cost-per-mile. It is the large amount of gallons of fuel consumed and/or miles driven that makes a big difference in revenue if multiplied a few cents in fuel tax or by the VMT fee.

In terms of revenue at the federal level, i.e., revenue to fund the Highway Trust Fund, the VMTfee is superior to the CPI-adjusted gasoline tax. Since there is no sales tax at the federal level, the $\mathrm{CPI}$-adjusted tax cannot generate as much revenue as in the state case. Figure 5 summarizes the differences in revenue across the different EIA cases and policy scenarios. Note that the differences are very large and that the current baseline, i.e., the current scenario represents the worst case scenario.

\section{Discussion and Conclusion}

An aspect that was excluded from our analysis is the cost of alternative taxing systems. Costs associated with operation, administration, collection, and enforcement can be substantial (TRB, 2011). By comparing average costs in various U.S. states and countries, TRB (2011) find that the 


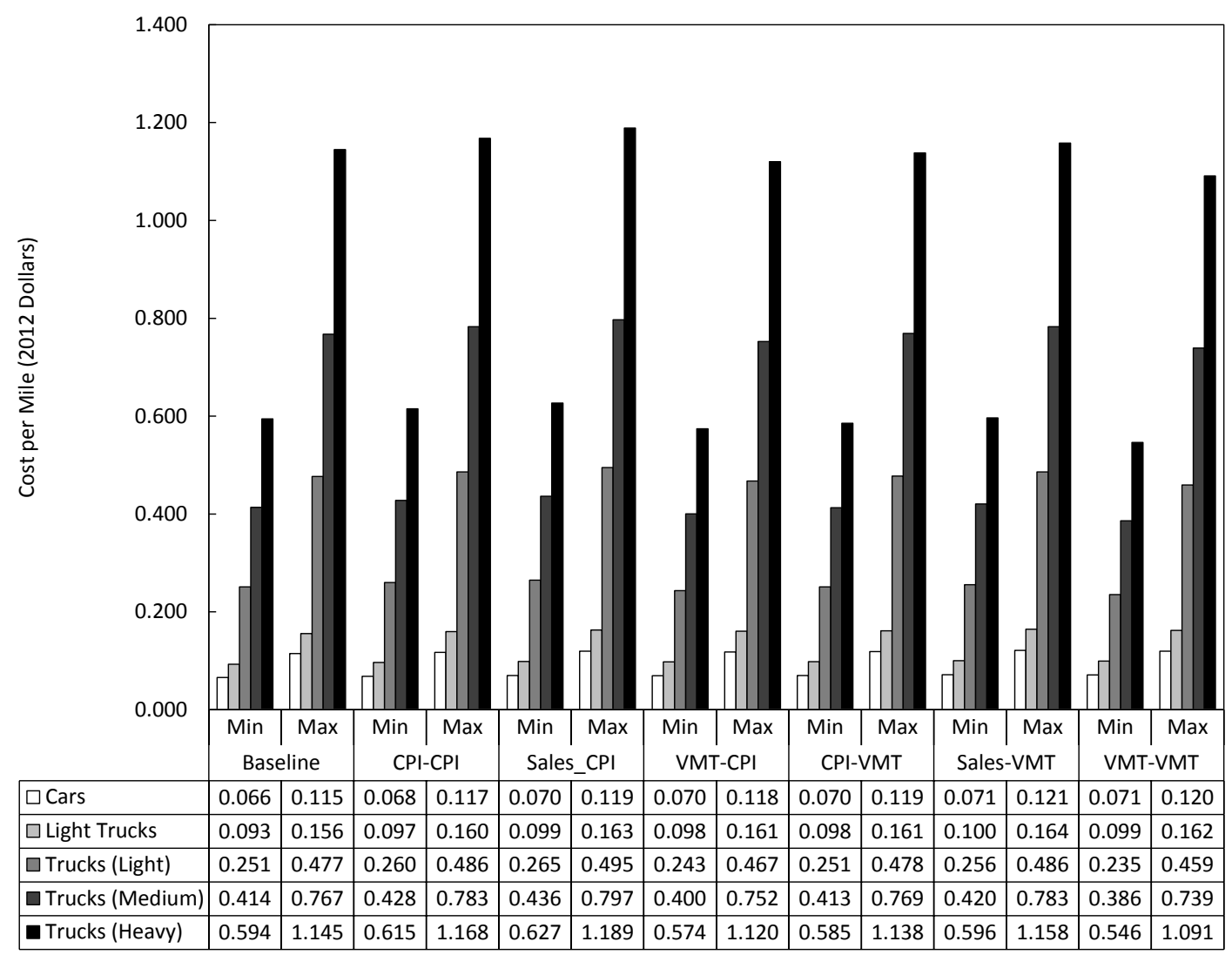

Figure 4: Sales-weighted cost per mile in 2040

costs supporting a particular revenue system are $0.92 \$, 33.5 \%$, and $6.6 \%$ of total revenue generated for fuel taxes, tolling, and VMT fees. The amount reported for the VMT fee is based on one year of reporting from the Netherlands and it is expected that a larger share of revenue would be spent on supporting the system in the United States (TRB, 2011). Given the results presented in the previous section, we hypothesize that even if a share larger than $6.6 \%$ is spent on operating a VMT-fee collection system, the additional revenue would still be higher than under the current fuel tax system for most states.

Linking fuel taxes to the cost of inflation would keep the tax rate constant over time but may be perceived as a tax increase and thus, would make its adoption more challenging from a political perspective. Despite being one-fifth of the average Western Europe tax rate, the increase of the U.S. gasoline tax by \$0.04 faced significant opposition in 1993 (Chernick and Reschovsky, 1997). A number of studies compare the motor fuel tax rate in the United States to its international industrial counterparts, pointing to significantly low level of motor fuel taxation in the United States, the lowest among industrial countries (Dunn, 1993; Wachs, 2003; Parry and Small, 2005). Parry and Small (2005) calculated the optimal gasoline tax rate in the United States - after including the 


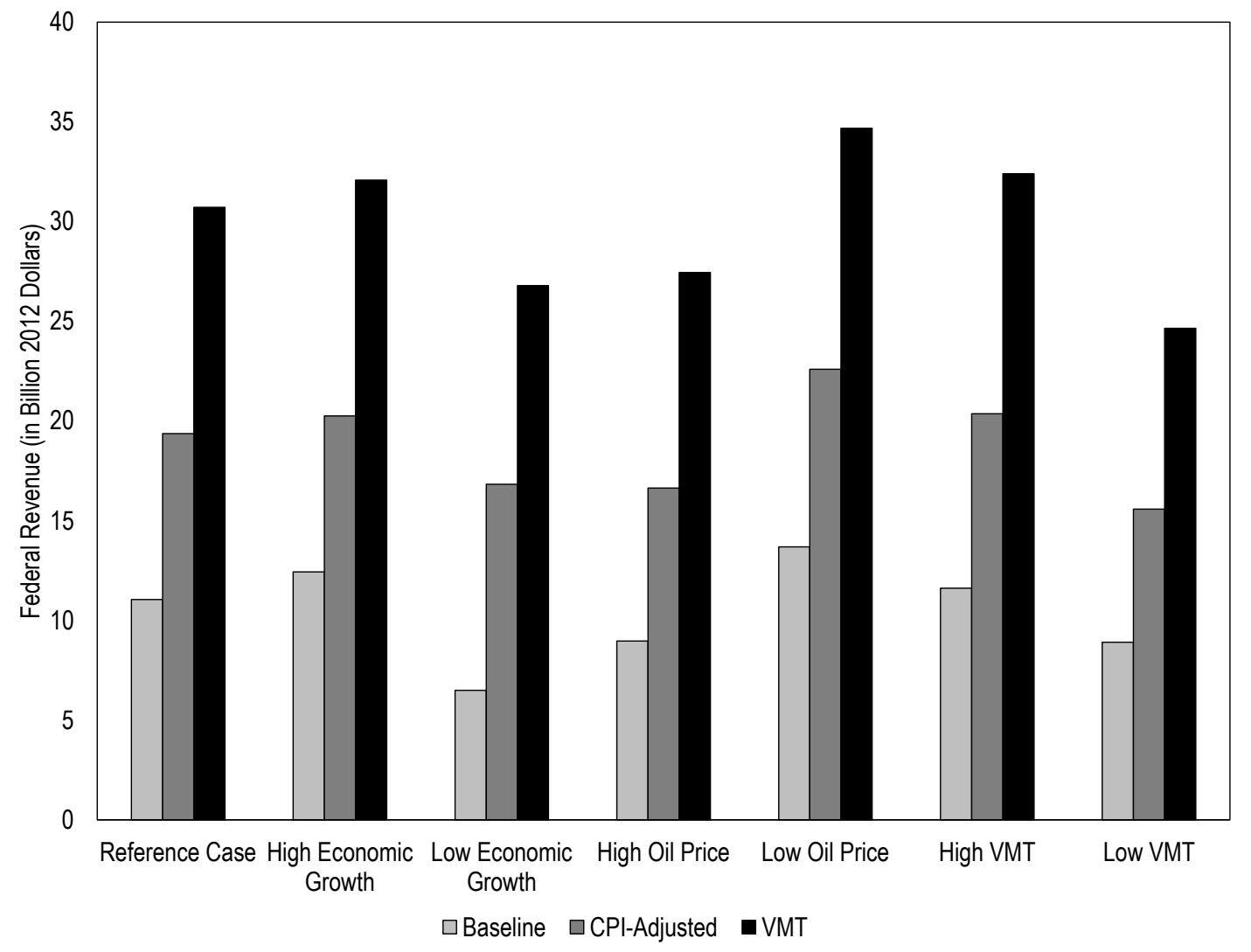

Figure 5: Federal revenue in 2040. Note that the average value is reported from the state policies, e.g., "CPI-Adjusted" represents the average value at the federal level of the scenarios "CPI/CPI," "Sales/CPI", and "VMT/CPI." The differences are negligible and thus, the average is an appropriate measure.

external costs of congestion, accidents, air pollution (air and global) as well as a "Ramsey Tax" component, i.e., the notion that the government should minimize excess burden in raising revenue when determining an optimal tax rate on a commodity - they arrived at the optimal gasoline tax rate of \$1.01 per gallon, more than twice the current rate. Delucchi (2007) compared all expenditures and payments made to maintain and build additional capacity within the U.S. transportation system and indicated that the fuel taxes and fees paid by motor vehicle users fell short of government expenditures (excluding external costs of motor vehicle use); this shortfall is approximately 20 to 70 cents per gallon for all motor vehicle users. Efforts were also made to evaluate the costs, in both monetary and non-monetary terms, of motor vehicle use to users of vehicles as well as those not borne by vehicle users. Ignoring the current need for a reform of transportation infrastructure funding will only compound the burden for future generations (NSTIFC, 2009).

Our analysis suggests that indexing fuel taxes to inflation or implementing a VMT-fee would 
address the challenge of financial sustainability by providing a revenue source that increases at or exceeds the rate of inflation between now and 2040. If states were to enact policies that link fuel taxes to a measure of inflation, state governments would arrest the decreasing purchasing power of their current revenue streams. While the fuel tax would remain constant in real terms, increases in population, real income, which ultimately drives up vehicle miles traveled, will result in increased revenue. However, the issue of increased fuel economy is not addressed by indexing fuel taxes to inflation. The VMT-fee could also be made a function of vehicle weight, fuel efficiency, type of road, and time-of-use. Especially the vehicle weight plays an important role since most of the road damage is done by heavy trucks. The damage done to road increases by the fourth power based on the weight put on the axles (TRB, 2007). The current fuel taxes takes the weight of a vehicle indirectly into account since heavier vehicles have a lower fuel economy. Nevertheless, since the increase in taxes paid due to the lower fuel economy is not proportional to the damage done to roads, fuel taxes are not efficient (Forkenbrock, 2005).

Several other issues enter the policy debate of changing the current motor fuel taxation scheme. First, our analysis does not address the path to implementation of a new revenue-generating system. NSTIFC (2009) suggest that the long-term system used in the U.S. is a VMT-fee but that this system needs to overcome political issues first. They suggest that in the meantime an increase in the gasoline and diesel tax can bridge short-term funding needs until privacy issues are resolved. Implementing a VMT-fee for federal and government can also lead to economies of scale since local governments can take advantage of the collection infrastructure set in place by the federal government. (Forkenbrock, 2005) suggest there will be a transition phase if a VMT fee is operated parallel to a motor fuel tax since not all vehicles can likely be switched to the new system at once. The authors suggest that only new vehicles would be equipped to track the vehicle miles traveled and thus, it would take 10 and 20 years to have $63 \%$ and $95 \%$ of vehicles on the road compatible with a VMT system, respectively. Some states and countries have already started to implement VMT taxes based also on weight. In the U.S., Oregon, New Mexico, New York, and Kentucky have implemented such a system; internationally, Germany, Switzerland, and Austria are examples of such a system for heavy trucks (McMullen et al., 2010).

The literature has also been concerned about the distributional effects of fuel taxes as opposed to a mileage fee. The current gasoline tax has been criticized for being regressive and putting a higher financial burden on low-income than on high-income households (Chernick and Reschovsky, 1997). Chernick and Reschovsky (1997) argues that the regressivity of the gasoline tax is potentially reduced by looking at lifetime income of households as opposed to cross-sectional income since consumers make consumption decision based on their expectations about their permanent income. The authors do not find evidence that the regressivity is substantially reduced since the upward mobility is limited. It is argued that a VMT fee would disproportionately hurt rural drivers since they travel further distances than urban drivers. However, McMullen et al. (2010) find that implementing a VMT could be beneficial to rural drivers since they usually drive cars with lower fuel economy.

Lastly, any attempt at the state or federal level to increase revenue through adjusting taxation schemes or implementing new taxing structures may be politically challenging. For example, a survey of local government officials in Indiana suggests that policymakers do not support increase in 
fuel taxes to support the construction and maintenance of local road infrastructure (IU PPI, 2013). Increasing fuel taxes was the second to least popular option among all respondents (falling only behind adopting tolls on local roads). Respondents were more likely to support revenue-neutral options that shifted state spending priorities and expanding local funding options. Duncan and Graham (2013) echo this finding in their national survey results that people are opposed to financing roads with VMT taxes, higher fuel taxes, sales and income taxes, and tolls. They speculate the high level of opposition is due to people's belief that roads are in good condition and a dislike for new (higher) taxes.

Despite diverging perspectives and standing, the conclusion that the U.S. surface transportation system will gradually deteriorate without a new or additional dedicated source of transportation funding is universal. We show that the current fuel tax system leads to a significant decrease in revenue over time and that linking it to inflation improve the revenue stream compared to the current system but still leads to a decrease over time since it is a function of fuel efficiency. Future research could address the possibility of replicating a VMT fee by imposing an inflation adjusted fuel tax and linking it to the average fuel economy of vehicles in the state or nation. Our analysis does not examine whether linking fuel taxes to inflation would sufficiently address the existing inadequacy of fuel and vehicle taxes to address the funding needs at the state level. Such an analysis would require an in-depth examination of each state's infrastructure needs and its associated costs to determine an optimal fuel tax rate; this effort falls outside of our analysis.

\section{Acknowledgments}

The authors thank the Soy Transportation Coalition for financial support.

\section{References}

Al-Alawi, B. M., Bradley, T. H., 2013. Total cost of ownership, payback, and consumer preference modeling of plug-in hybrid vehicles. Applied Energy 103, 488-506.

API, January 2016. January 2016 state motor fuel taxes by state. Report, American Petroleum Institute.

Austin, D., Dinan, T., 2005. Clearing the air: The costs and consequences of higher CAFE standards and increased gasoline taxes. Journal of Environmental Economics and Management 50, $562-582$.

Bento, A. M., Goulder, L. H., Jacobsen, M. R., von Haefen, R. H., 2009. Distributional and efficiency impacts of increase US gasoline taxes. American Economic Review 99 (3), 667-699.

CBO, 2008. Effects of gasoline prices on driving behavior and vehicle markets. Report 2883, Congress of the United States Congressional Budget Office. 
CBO, 2011a. Alternative approaches to funding highways. Report 42409075, Congress of the United States Congressional Budget Office.

CBO, 2011b. The Highway Trust Fund and Paying for Highways. Testimony 4275, Congress of the United States Congressional Budget Office.

CBO, 2013. Status of the highway trust fund. Testimony 4819, Congress of the United States Congressional Budget Office.

CBO, 2015. The Status of the Highway Trust Fund and Options for Paying for Highway Spending. Testimony, Congress of the United States Congressional Budget Office.

Chernick, H., Reschovsky, A., 1997. Who pays the gasoline tax? National Tax Journal 50 (2), 233-259.

Cooper, J. C., 2003. Price elasticity of demand for crude oil: estimates for 23 countries. OPEC Review 27 (1), 1-8.

Delucchi, M. A., 2007. Do motor-vehicle users in the U.S. pay their way? Transportation Research Part A: Policy and Practice 41 (10), 982-1003.

DOT, 2015. Ethanol. http://www. fueleconomy.gov/feg/ethanol.shtml, accessed 14 February 2015.

Dumortier, J., Kent, M. W., Payton, S. B., 2015. Plug-in vehicles and the future of road infrastructure funding in the united states. IU SPEA AgEcon Papers 4.

Duncan, D., Graham, J. D., 2013. Road user fees instead of fuel taxes: The quest for political acceptability. Public Administration Review 73 (3), 415-426.

Dunn, J. A., 1993. The politics of motor fuel taxes and infrastructure funds in france and the united states. Policy Studies Journal 21 (2), 271-284.

EIA, April 2014. Annual energy outlook 2014 with projections to 2040. Tech. Rep. DOE/EIA0383(2014), U.S. Energy Information Administration.

EIA, September 2015. Federal and state motor fuel taxes. http://www.eia.gov/petroleum/ marketing/monthly/xls/fueltaxes.xls accessed on 11 February 2016.

EIA, 2016. State energy data system (seds). http://www. eia.gov/state/seds/ accessed on 11 February 2016.

EPA \& NHTSA, 2012. 2017 and later model year light-duty vehicle greenhouse gas emissions and corporate average fuel economy standards. Final rule Vol. Federal Register 77:199, pp. 6262363200, US Environmental Protection Agency \& National Highway Traffic Safety Administration. 
Espey, M., 49-60 1996. Explaining the variation in elasticity estimates of gasoline demand in the united states: A meta-analysis. Energy Journal Energy Journal (17), 3.

FHWA, 2014. Highway Statistics 2014: Status of the Federal Highway Trust Fund 19572012. https://www. fhwa.dot.gov/policyinformation/statistics/2014/, accessed 19 March 2016.

Forkenbrock, D. J., 2005. Implementing a milage-based road user charge. Public Works Management and Policy 10 (2), 87-100.

FTA, 2015. State motor fuel excise tax rates. http://www.taxadmin.org/assets/docs/ Research/Rates/mf.xls accessed on 11 February 2016, federation of Tax Administrators.

Gale, W. G., Brown, S., 2013. Tax reform for growth, equity, and revenue. Public Finance Review $41,721-754$.

Goldman, T., Wachs, M., 2003. A quiet revolution in transportation finance: The rise of local option transportation taxes. Transportation Quarterly 57 (1), 19-32.

Gomez, J., Vassallo, J. M., 2013. Comparative Analysis of Road Financing Approaches in Europe and the United States. Journal of Infrastructure Systems 20 (3), 04014008.

Greene, D. L., 2011. What is greener than a VMT tax? The case for an indexed energy user fee to finance U.S. surface transportation. Transportation Research Part D: Transport and Environment $16,451-458$.

Hughes, J. E., Knittel, C. R., Sperling, D., 2008. Evidence of a shift in the short-run price elasticity of gasoline demand. Energy Journal 29 (1), 113-134.

IU PPI, July 2013. Intergovernmental issues in Indiana: 2012 IACIR Survey. Indiana advisory commission on intergovernmental relations (iacir) report, Center for Urban Policy and the Environment, Indiana University Public Policy Institute.

Leard, B., Linn, J., McConnell, V., Raich, W., 2015. Fuel Costs, Economic Activity, and the Rebound Effect for Heavy-Duty Trucks. Discussion Paper RFF DP 15-43, Resources for the Future.

McMullen, B. S., Zhang, L., Nakahara, K., 2010. Distributional impacts of changing from a gasoline tax to a vehicle-mile-tax for light vehicles: A case study of Oregon. Transport Policy 17, 359-366.

NSTIFC, February 2009. Paying our way: A new framework for transportation finance. Report, National Surface Transportation Infrastructure Financing Commission.

Park, S. Y., Zhao, G., 2010. An estimation of us gasoline demand: a smooth time-varying cointegration approach. Energy Economics 32 (1), 110-120. 
Parry, I. W., April 2006. How should heavy-duty trucks be taxes? Discussion Paper RFF DP 06-23, Resources for the Future.

Parry, I. W., Small, K., 2005. Does britain or the united states have the right gasoline tax? American Economic Review 95 (4), 1276-1289.

Puentes, R., Prince, R., 2003. Fueling transportation finance: A primer on the gas tax. Tech. Rep. March, Brookings Institution.

Schank, J., Rudnick-Thorpe, N., 2011. End of the Highway Trust Fund? Long-term options for funding federal surface transportation. Transportation Research Record: Journal of the Transportation Research Board 2221, 1-9.

TRB, 2006. The fuel tax and alternatives for transportation funding. Special Report 285, Transportation Research Board of the National Academies.

TRB, July 2007. Pavement lessons learned from the aasho road test and performance of the interstate highway system. Transportation Research Circular E-C118, Transportation Research Board of the National Academies.

TRB, 2011. Costs of alternative revenue-generation systems. National Cooperative Highway Research Program (NCHRP) 689, Transportation Research Board of the National Academies.

U.S. DOE Alternative Fuels Data Center, 2015. Fuel properties comparison. http://www . afdc . energy.gov/fuels/fuel_properties .php, accessed 26 January 2015.

U.S. DOT Bureau of Transportation Statistics, 2015. Table 4-23: Average fuel efficiency of u.s. light duty vehicle. http://www.rita.dot.gov/bts/sites/rita.dot.gov.bts/files/ publications/national_transportation_statistics/html/table_04_23.html, accessed 26 January 2015.

USPIRG, August 2013. Moving of the road: A state-by-state analysis of the national decline in driving. Tech. rep., U.S. Public Interest Research Group Education Fund.

Wachs, M., 2003. A dozen reasons for gasoline taxes. Public Works Management \& Policy 7 , $235-242$.

Wachs, M., April 2006. A quit crisis in transportation finance. Testimony CT-260, Rand Corporation. 